\title{
Erosion characteristics and floc strength of Athabasca River cohesive sediments: towards managing sediment-related issues
}

\author{
Juan Garcia-Aragon • Ian G. Droppo • \\ B. G. Krishnappan • Brian Trapp • Christina Jaskot
}

Received: 15 September 2010 / Accepted: 25 February 2011 /Published online: 23 March 2011

(C) Her Majesty the Queen in Right of Canada 2011

\begin{abstract}
Purpose This research aims to investigate: (1) the evolutional sequence of erosion of cohesive sediments entering the Athabasca River, (2) the influence of consolidation/ biostabilization time on bed sediment stability, and (3) the implication of these results on contaminant transport within the Athabasca River.

Materials and methods A 5-m annular flume was used to generate bed shear to assess cohesive sediment dynamics for eroded beds with consolidation/biostabilization periods (CBs) of 1, 3, and 7 days. Additional laser particle sizing, image analysis, densitometry, and microbial analysis were employed to further the analysis with respect to bed erosion and eroded floc characteristics.

Results and discussion The critical bed shear stress for erosion increased from 0.16 (1-day CB) to $0.26 \mathrm{~Pa}$ (7-day $\mathrm{CB})$ with an inverse relationship observed for both suspended sediment concentration and erosion rate with respect to CBs. The 7-day CB yielded the largest eroded flocs that initially have high organic content but were quickly broken up with increasing shear. The strongest eroded floc population occurred for the 3-day CB. Eroded flocs were found to be of an open matrix with high water content and low density. Flocs contained a mixture of clay and silt particles, microbes, algae, diatoms, and secreted extracellular polymeric substances (EPS). Counts of bacte-
\end{abstract}

Responsible editor: Sabine Ulrike Gerbersdorf

J. Garcia-Aragon

Centro Interamericano de Recursos del Agua, FI-UAEM,

Toluca, Mexico

I. G. Droppo $(\bowtie) \cdot$ B. G. Krishnappan • B. Trapp • C. Jaskot

Environment Canada, CCIW-Burlington,

Burlington, ON L7R 4A6, Canada

e-mail: ian.droppo@ec.gc.ca ria were observed to decrease with CBs while an increase in the algal community is suggested with time.

Conclusions Consolidation was believed to have limited effect on erosion while biostabilization was the main controlling factor. Increasing biostabilization with time resulted in a more stable surficial layer with a reduced erosion rate relative to less biostabilized beds. The highly biostabilized bed (7-day CB), however, yielded the largest flocs which broke up easily compared to those eroded from 1- and 3-day CBs. It is believed that the EPS produced by the sediment biological community is the main component of the bed and flocs that is responsible for the observed stability results.

Keywords Athabasca River - Cohesive sediments · EPS . Erosion · Floc strength $\cdot$ Microbes $\cdot$ Rotating annular flume SFGL

\section{Introduction}

Cohesive sediments can play an important physical, chemical, and biological role in regulating river ecosystem quality. As many pollutants, including polycyclic aromatic hydrocarbons (PAHs), can be highly associated with the cohesive sediment fraction $(<63 \mu \mathrm{m})$ (Ghosh et al. 2000; Maruya et al. 1996), the sediment dynamics (erosion, transport, and deposition) within the Athabasca River, Canada will strongly influence the river's contaminant dynamics (Stone et al. 2008). Of particular relevance to the Athabasca River, are concerns about the anthropogenic and natural PAHs (Headley et al. 2001) derived from tar sands exploitation or natural sources within the basin. Often, PAHs bound to cohesive sediments can be highly bioavailable (Ghosh et al. 2000), necessitating the need to gain a 
better understanding of the system's sediment dynamics for risk and impact assessment.

Typical of many river systems is a structurally unique surficial layer of sediment called the surface fine-grained lamina (SFGL) or surface floc layer (Droppo et al. 2001; Droppo and Stone 1994; Lambert and Walling 1988). This layer is often transient and of a low density and high water content which blankets over the existing bed between erosion events. Much of the SFGL is formed by the deposition of particles in the flocculated state (Droppo and Amos 2001) which are highly biological in composition (Gerbersdorf et al. 2007). The SFGL and any associated contaminants, depending on the time between erosion events, may be incorporated into the underlying sediment through self-weighted consolidation (Teisson et al. 1993) and biostabilization (Gerbersdorf et al. 2009).

It is this structural difference within bed sediments that will have a strong influence on how they erode and, as such, on the amount of sediments and contaminants mobilized and transported down the river. Typically, the SFGL will erode at a bed shear stress substantially lower than the underlying sediment (Droppo 2009). The initial erosion of the SFGL has been termed Type Ia erosion, while the higher shear required to initiate the erosion of deeper more consolidated sediment is referred to as Type $\mathrm{Ib}$ erosion. Type Ia has been called surface erosion and is associated with the release of flocs, while Type Ib has been referred to as mass or bulk erosion and is characterized by the release of aggregates (Amos et al. 2003, 2004). Both types of erosion have been shown to be highly influenced by the degree of biofilm development (biostabilization) with substantially more energy required to erode microbial mediated sediment than purely mineral sediment (Gerbersdorf et al. 2008; Krumbein et al. 1994). Regardless of the type of erosion, PAH-loaded sediments may be moved in a transient fashion of successive erosion and deposition episodes in association with storm events. The fate of the eroded sediment and contaminants will be dictated by their downward flux which will be controlled by both fluid shear and floc structure/architecture (Liss et al. 1996). Therefore, the structure and composition of eroded flocs and their interaction with fluid shear during transport is an important issue to understand, and this is often overlooked in many studies of sediment erosion, transport, and fate (Droppo 2004). The transient movement of sediments may have detrimental effects on both the river ecosystem and, more specifically for the Athabasca River, on the downstream receiving Lake Athabasca delta.

In this study, a laboratory 5-m annular flume was used to assess the stability of recently deposited cohesive sediment collected from the Muskeg River at the confluence with the Athabasca River near Fort McMurray, Alberta, Canada. Three experimental runs were performed on the sediment with increasing consolidation/biostabilization periods $(1,3$, and 7 days). The objectives of these experiments were to: (1) assess the evolutional sequence of erosion of cohesive sediments entering the Athabasca River, (2) to evaluate the influence of consolidation/biostabilization time on bed sediment stability and eroded floc structure, and (3) to discuss the implication of these results on contaminant transport within the Athabasca River.

\section{Materials and methods}

\subsection{Sediment sample collection and preparation}

Bed sediment samples were collected on the Muskeg River at the confluence of the Athabasca River on October 6-7, 2009 near Fort McMurray, Alberta. The Muskeg River was chosen for sampling as it is: (1) small in size (10 m wide, $0.5 \mathrm{~m}$ deep at point of sampling), thus providing easier access for SFGL sampling, and (2) the Muskeg River basin possesses extensive deposits of presently surface mined bitumen and is therefore also a potential significant source of PAHs to the Athabasca River.

Recently deposited SFGL over a coble bed substrate was collected using an inverted cone sampler (Krishnappan 2007). This sampler consists of a conical chamber fitted with a propeller to induce sediment erosion and a submerged pump to pump the resuspended sediment and water to $100 \mathrm{~L}$ polyethylene containers. While wading, the sampler was manually lowered to the bed and gently moved several times during the collection process. In all, $800 \mathrm{~L}$ of water and sediment was collected. A further five 20-L polyethylene containers were filled with deposited mud collected from the margins of the river. All containers were shipped from Fort McMurray to Environment Canada, Burlington, Ontario in a refrigerated truck $\left(4^{\circ} \mathrm{C}\right)$ where they were kept refrigerated $\left(4^{\circ} \mathrm{C}\right)$ prior to the start of flume experiments.

\subsection{Erosion experiments}

The annular flume used to assess erosional characteristics consisted of a circular channel, $5.0 \mathrm{~m}$ in diameter, $0.30 \mathrm{~m}$ in width, and $0.30 \mathrm{~m}$ in depth. Flow was generate in the flume through the counter rotation of the circular channel (clockwise) containing the experimental sediment bed and overlying water, relative to a top lid (counter clockwise) that just touched the surface of the water within the flume. This counter rotation helped to generate a two-dimensional turbulent shear flow with nearly constant bed shear stress across the width of the channel (Petersen and Krishnappan 1994). A full description of the flume can be found in Krishnappan (1993). 
The flume was interfaced with a CILAS ${ }^{\mathrm{TM}} 930$ laser particle size analyzer (S.P.E. Ltd., North York, ON, Canada) to generate real-time particle size distributions during flume operation (a distribution was measured every $7 \mathrm{~min}$ over the duration of an experimental run). The instrument operates on the principle of laser diffraction and was operated in a continuous flow through mode and generates distributions ranging from 0.2 to $500 \mu \mathrm{m}$ in range. To minimize floc breakage in the system, samples were drawn through the system (i.e., flocs did not pass through a pump prior to analysis). While some floc breakage cannot be discounted, the degree of breakage will be highly dependent on the structure/composition of the flocs. It is believed that for the sediment analyzed, minimal breakage occurred given the observed increasing size with shear at the start of the experiment.

The sediment/water samples were allowed to equilibrate to room temperature at which point they were hydraulically sieved through a 200- $\mu \mathrm{m}$ mesh. The resulting sediment (that which passed through the mesh) was placed in the circular channel forming a uniform 2-cm bed. (Particles larger than $200 \mu \mathrm{m}$ were removed to assess the true effects of the finer sediments as a large mix of sediment sizes were within the bed up to and including cobles. In addition, finer particles are also more relevant to contaminant transport). The flume was then filled with Muskeg River water to a depth of $12 \mathrm{~cm}$ and operated at a high rate of speed equivalent to a bed shear of $0.461 \mathrm{~Pa}$ for $20 \mathrm{~min}$. The speed of the flume was then reduced gradually to a stop at which point the sediment was allowed to settle and consolidate/ biostabilize for 1-, 3-, and 7-day periods (individual consecutive experiments). The same sediment and water mixture was used for all experimental runs as: (1) while some bio-physicochemical changes were likely to occurred within the flume over the duration of the experiments $(1,3$, and 7 days), it was felt that by maintaining a consistent core sediment for all experiments, extraneous variables and unknown variations in sediment and water characteristics were minimized, than if new material was added for each experiment, and (2) this was a logistical necessity, as the volumes required for the flume are large (approx. $100 \mathrm{~kg}$ sediment and $800 \mathrm{~L}$ water), thus making sampling and long-range shipping problematic and costly.

Erosion experiments were initiated from quiescent conditions in incremental steps of shear ranging from $20 \mathrm{~min}$ (initial steps) to $40 \mathrm{~min}$. The shear stresses and times used were: $0.058 \mathrm{~Pa}(20 \mathrm{~min}), 0.088 \mathrm{~Pa}(20 \mathrm{Min})$, $0.121 \mathrm{~Pa}(40 \mathrm{~min}), 0.165 \mathrm{~Pa}(40 \mathrm{~min}), 0.21 \mathrm{~Pa}(40 \mathrm{~min})$, $0.265 \mathrm{~Pa}$ (40 $\mathrm{min})$, and $0.325 \mathrm{~Pa}(40 \mathrm{~min})$. Fifty-milliliter samples of water and eroded floc were collected from the flume through a sampling port located at the mid-depth at 5 -min intervals until the completion of the test. These samples were analyzed for suspended solid (SS) concen- tration by a gravimetric method, which consisted of filtering $(0.45 \mu \mathrm{m})$ the sample, and drying and weighing the residue.

Erosion rate, $E$ (kilograms per square meter per second), was calculated following the method of Ravens and Gschwend (1999) (Eq. 1):

$E=M\left(\tau-\tau_{c}\right)$

where $\tau_{c}$ is the critical shear stress for erosion and $\tau$ is the applied shear stress. $M$ is the erosional constant rate (kilograms per square meter per second per pascal). $M$ was calculated for each shear stress as the average of the resuspension sediment rate over the applied shear stress range used in the experiments. The experimental values of $M$ are as follows: 1 -day $-0.135,3$-day -0.065 , and 7-day0.037 .

\subsection{Bulk density}

Bulk density analysis was performed on all three consolidation/biostabilization periods. Samples were settled for 1, 3 , and 7 days within $12 \mathrm{~cm}$ of water in three glass beakers forming a similar bed thickness to the flume. Bulk density profiles were measured at 1-mm increments using an Ultra High Concentration (UHC) meter manufactured by Delft Hydraulics, The Netherlands (Berkhout 1994). This analysis was limited to the region starting $5 \mathrm{~mm}$ below the surface of the sediment (the ultrasound generator and receptor were $10 \mathrm{~mm}$ in diameter and must be fully submerged for proper measurement).

\subsection{Image analysis of floc properties and settling velocity}

Additional water samples were collected in plankton chambers from the sampling port following the methods of Droppo et al. (1997) at the end of each experimental run to evaluate changes in geometric properties of suspended solids using multiple microscopes and techniques [Conventional Optical Microscopy (COM), Environmental Scanning Electron Microscopy (ESEM), and Transmission Electron Microscopy (TEM)]. Eroded floc settling velocity, porosity, and density were determined using the settling column method described by Droppo et al. (1997).

\subsection{Bacteria counts}

Triplicate 500-ml samples were collected in autoclaved sample bottles for the determination of total bacterial counts in suspension at the University of Guelph, Ontario, Canada, using standard heterotrophic plate counting procedures (standard method 9215: Eaton et al. 2005). Biostabilization of the sediment deposits were further visually assessed by 
direct observation through the windows in the walls of the annular flume prior and during each experiment.

\subsection{POC and DOC}

Triplicate $100 \mathrm{ml}$ samples were collected from the flume sampling port into glass containers. All particulate organic carbon (POC) and dissolved organic carbon (DOC) analysis was done by the National Laboratory for Environmental Testing in Burlington, Ontario, Canada following the standard method of Environment Canada (1994).

\section{Results}

\subsection{Critical bed shear stress for erosion}

Figure 1 provides the calibrated time-series plots generated from the 5-m annular flume for all three consolidation/ biostabilization periods (hereafter referred to as $\mathrm{CBs}$ ) and illustrates the change in SS concentration with increasing bed shear stress over time. The plot demonstrates an inverse relationship between $\mathrm{CBs}$ and SS concentrations (less sediment is eroded as CBs increase). Figure 1 and Table 1 also illustrate the classic erosion sequence of types Ia and $\mathrm{Ib}$ and further illustrate the influence of CBs on erosion. During type Ia erosion, SS concentrations increase slowly (due to the limited material available); however, the rate of erosion increases significantly once type $\mathrm{Ib}$ erosion is reached. To assess and model from the onset of SFGL erosion, type Ia erosion was considered to be the critical bed shear stress for erosion $\left(\tau_{c}\right)$, even though more sediment will be mobilized during type Ib erosion.

\subsection{Erosion rate and density gradients}

Similar to the change in eroded SS concentration with CBs, Fig. 2 shows that the erosion rate also has an inverse

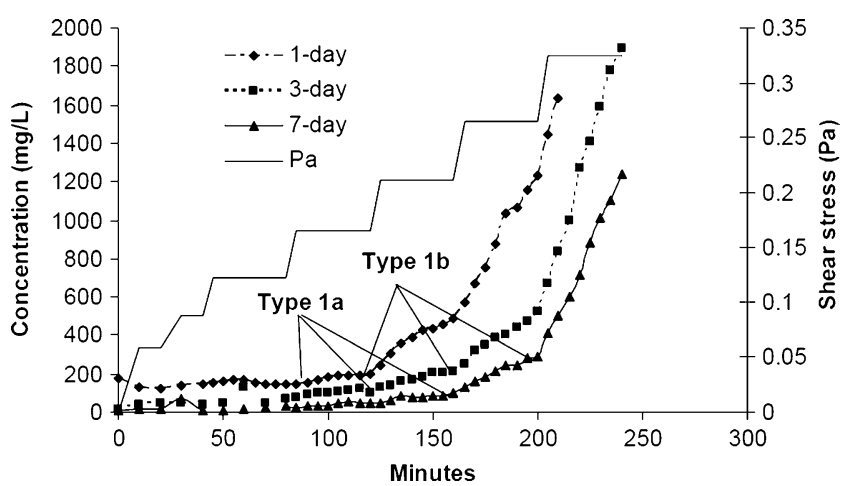

Fig. 1 Change in SS concentration with increasing shear stress for all consolidation/biostabilization periods. Type Ia and $\mathrm{Ib}$ erosion thresholds are indicated
Table 1 Type Ia and Ib erosion shears for each consolidation/ biostabilization period

\begin{tabular}{lcc}
\hline $\mathrm{CBs}$ & Erosion type Ia $\tau_{\mathrm{c}}(\mathrm{Pa})$ & Erosion type $\mathrm{Ib}(\mathrm{Pa})$ \\
\hline 1 day & 0.16 & 0.21 \\
3 days & 0.21 & 0.26 \\
7 days & 0.26 & 0.32 \\
\hline
\end{tabular}

relationship to CBs. For example, at a shear stress of $0.325 \mathrm{~Pa}(240 \mathrm{~min})$, the 3-day $\mathrm{CB}$ had an erosion rate 3.5 times larger than that at the 7-day CB.

Realizing the limitations of the UHC meter (unable to resolve the top $5 \mathrm{~mm}$ of sediment), there was no change in voltage (at a constant ultrasound output) with depth (from 5 to $20 \mathrm{~mm}$ depth) within or between the 1-, 3-, and 7-day CBs, suggesting no difference in density with depth; if consolidation were to occur, one would expect to have a change in density at these deeper layers (data not shown).

\subsection{Floc strength}

Floc strength, assessed most often within the wastewater industry, has generally been equated to the level of energy (velocity gradient) required to change a floc size distribution (Jarvis et al. 2005). The empirical expression for the relationship between the velocity gradient and the floc size according to Parker at al. (1972) is

$D_{50}=C G^{-\Psi}$

where $D_{50}$ is the medium floc diameter after applying a velocity gradient of $G$ (per second) for a time long enough to obtain a steady state. $C$ is the floc strength coefficient and $\Psi$ is the floc strength constant.

Equation 2 can be expressed as a $\log -\log$ plot as follows:

$\log D_{50}=\log C-\Psi \log G$

In this relationship, $\log C$ values are given by the intercept and $\Psi$ by the slope of the trend line (Fig. 3 and Table 2). The higher the value of $\log C$, the stronger the

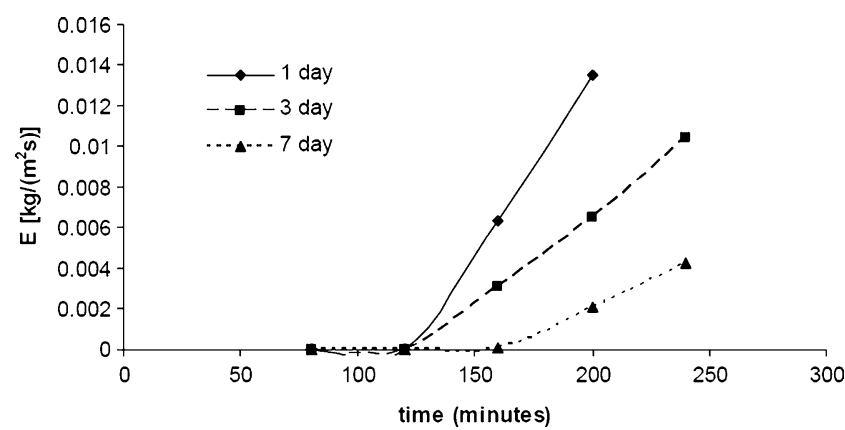

Fig. 2 Experimental erosion rate $(E)$ for different consolidation/ biostabilization periods 
Fig. 3 Experimental results of velocity gradient versus $D_{50}$ remaining before a change in the incremental shear rate, for each consolidation/biostabilization period

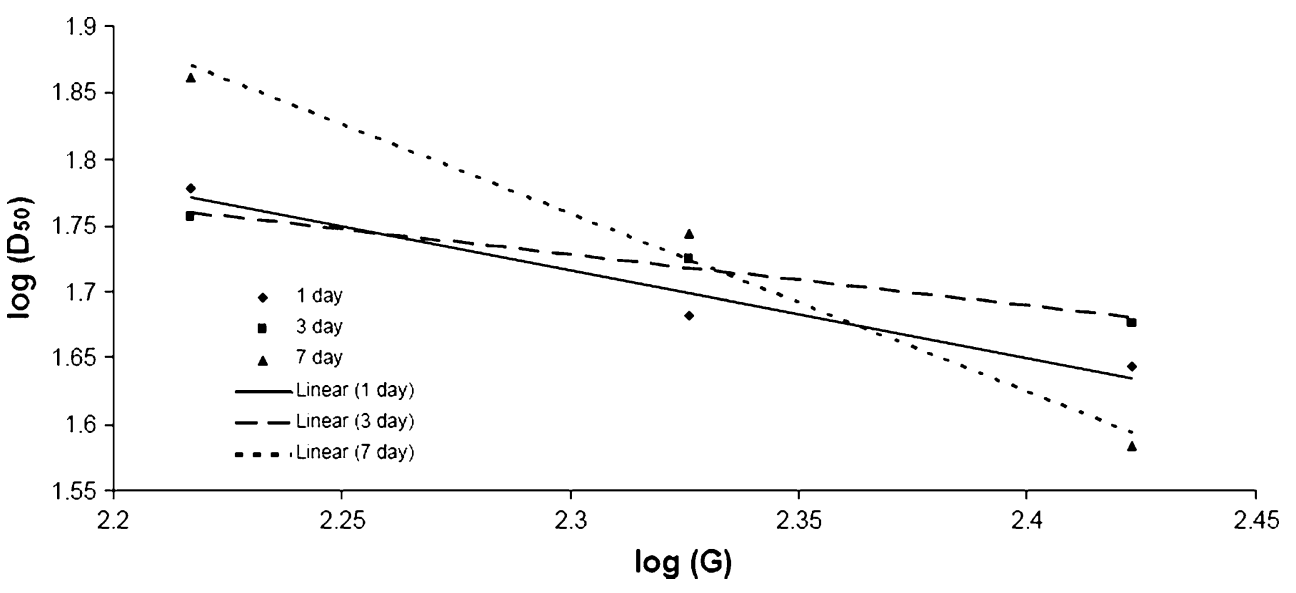

eroded floc at a fixed shear rate is (Francois 1987; Parker et al. 1972). Conversely, the higher the value of $\Psi$, the more prone the eroded flocs are to breakage under increasing shear (Jarvis et al. 2005). Note that as this analysis is relevant only for floc breakage periods, not all shear values could be incorporated into the analysis. As seen in Fig. 5 (discussed below), the 1- and 3-day CBs only showed floc breakage during the last three shears applied $(0.16$ to $0.26 \mathrm{~Pa}$ ) while the 7-day $\mathrm{CB}$ underwent floc breakage from the first shear value $(0.09 \mathrm{~Pa})$. For statistical comparisons between $\mathrm{CBs}$, however, only the last three shears were assessed for the 7-day CB (see Fig. 3).

Figure 3 and Table 2 show that 7-day CB flocs were the strongest at low shear but were more prone to breakage at higher shear levels (i.e., larger floc sizes at low shear but smaller floc sizes at higher shear relative to 1- and 3-day $\mathrm{CBs})$. The 3- and 1-day CBs possessed lower rates of change in floc size with increasing shear (i.e., lower values of $\Psi$ ), suggesting that they may have stronger bonds. The 3-day CB possessed the most stable floc at any shear as evidenced by the lowest slope $(\Psi)$ (i.e., minimal change in floc size with shear). The 1- and 3-day CBs had more similar $\Psi$ and $\log C$ values relative to the 7-day CB. Following the statistical approach of Larkin (1978) based on the $t$ statistic, all $\Psi$ and $\log \mathrm{C}$ were statistically different between CBs ( $t$-test, $p=0.05)$.

\subsection{Eroded floc characteristics}

In general, all eroded flocs, regardless of CBs, were of an open matrix with high water content (Fig. 4a), although initially the 7-day CB flocs were substantially larger with more organic content. Quiescent settling of the cohesive bed material (see Fig. 4b) showed a mean settling velocity, porosity, and density of $6.1 \mathrm{~mm} \mathrm{~s}^{-1}, 75 \%$, and $1.2 \mathrm{gcm}^{-3}$, respectively (based on two settled samples of 100 flocs greater than $100 \mu \mathrm{m}$ in diameter-lower limit due to resolution of imaging system). Figure 5 provides the median particle size variation measured with the CIL$\mathrm{AS}^{\mathrm{TM}}$ and demonstrates that while the 1- and 3-day $\mathrm{CBs}$ yielded similar $D_{50}$ values over erosion time, the 7-day CB was substantially different (similar to results shown in Fig. 3). The initial larger size for the 7-day $\mathrm{CB}$ was followed by a rapid decline in $D_{50}$ below that of the 1 - and 3-day CBs, although the slopes of the lines became similar. It is of interest to note in Fig. 5 that there was an initial rise in eroded floc $D_{50}$ for the first $70 \mathrm{~min}$ for 1 - and 3-day CBs followed by a gradual decline (floc breakage) with shear.

Direct visual observation through the window of the flume showed significant variation in the eroded flocs for the 7-day CB. In this case, very large "stringers" of integrated biofilm and flocs up to centimeters in length were initially observed with the onset of erosion (stringers are indicative of likely algal growth in the system Droppo et al. 2007). Higher resolution TEM (Fig. 6) does reveal the significance of the organic material within all eroded floc matrices regardless of $\mathrm{CB}$. Within this figure, both microbial cells and significant quantities of extracellular polymeric substances (EPS) are observed to be prominent structural features of the eroded flocs. ESEM microscopy (Fig. 7) further shows the presence of diatoms, organic

Table 2 Summary of floc strength coefficients and constants for different consolidation/biostabilization periods

\begin{tabular}{llrr}
\hline Consolidation time & Linear fit & Correlation coefficient & $\Psi$ \\
\hline 1 day & $\log \left(D_{50}\right)=-0.66 \log (G)+3.24$ & $r^{2}=0.96$ & 0.66 \\
3 days & $\log \left(D_{50}\right)=-0.39 \log (G)+2.62$ & $r^{2}=0.98$ & 3.24 \\
7 days & $\log \left(D_{50}\right)=-1.34 \log (G)+4.85$ & $r^{2}=0.98$ & 0.39 \\
\hline
\end{tabular}


Fig. 4 a Representative flocs from 1-day consolidation/biostabilization eroded at a shear of $0.165 \mathrm{~Pa}$ and $\mathbf{b}$ settling velocity of collected bed sediment prior to bed formation for 1-day consolidation/biostabilization period a

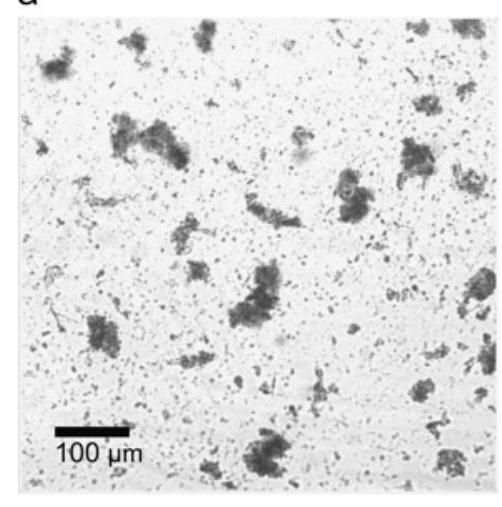

b

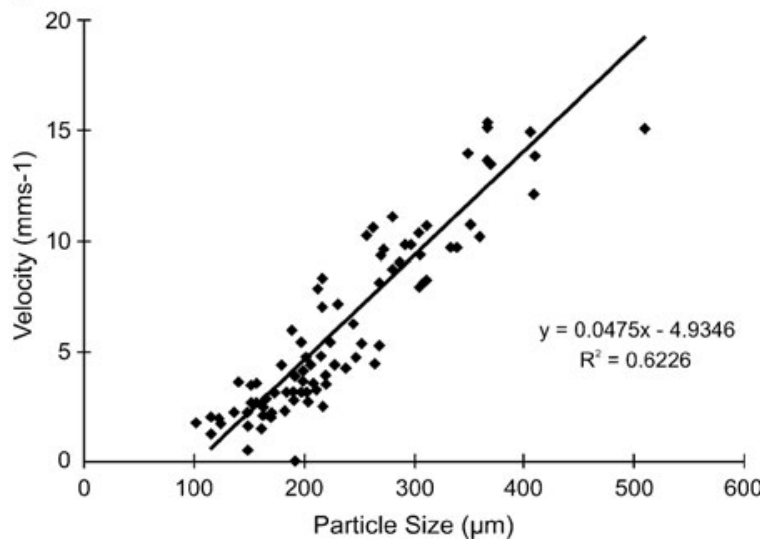

coatings, and a progression towards more elongated open matrix flocs for the 7-day CB.

\subsection{Microbial counts}

Mean values of total bacteria counts $(n=3)$ collected at the end of each run showed an inverse relationship between mean bacteria counts and CBs (1-day $2.3 \times 10^{4} \mathrm{cfu} \mathrm{mL}^{-1}, 3$ day $1.3 \times 10^{4} \mathrm{cfu} \mathrm{mL}^{-1}$, and $4.5 \times 10^{3} \mathrm{cfu} \mathrm{mL}^{-1}$ ).

\subsection{Eroded POC and DOC}

Table 3 provides the results for eroded POC and DOC in conjunction with SS concentrations. POC was highly influenced by the amount of sediment eroded, with the highest values corresponding to high SS concentrations. The complicating influence of this autocorrelation was minimized by viewing the ratio of values from the start of erosion to the end of the experiments. POC values increased by almost 35 times for the 7-day CB compared to an almost nine times increase for the 1-day CB in spite of SS concentrations being lower (at any given time) for the 7day $\mathrm{CB}$ relative to the other experimental runs. DOC remained relatively unchanged from start to finish for all CBs with concentrations increasing only marginally between CBs.

\section{Discussion}

In the study of sediment and contaminant erosion, transport, and fate, it is important to assess the likelihood of sediment mobilization by periodic flood events as, once suspended, these contaminated sediments may be transported to environmentally sensitive areas with detrimental impacts. Further, once suspended, the sediment (floc) structure in relation to the energy regime imparted onto the flocs will play a strong role in their fate. The results presented in this study illustrate the dynamic nature of eroded cohesive sediment in relation to shear levels and the duration of compaction and/or biostabilization.

The bulk density measurements within this research showed no difference in density at depths between 5 and $20 \mathrm{~mm}$ regardless of CBs. While the density of the upper most $5 \mathrm{~mm}$ was not measured (limitation of UHC), the constant density even after 7 days suggest that likely no dewatering and self-weighted consolidation is occurring at these lower layers. For the upper SFGL, Hawley (1982) has shown that, while rapid consolidation occurs in the first hour after deposition, very little additional consolidation occurs over the next $24 \mathrm{~h}$ and that a minimum thickness of $10 \mathrm{~mm}$ is required for consolidation. As our system only consists of a $2-\mathrm{cm}$ bed with $12 \mathrm{~cm}$ of overlaying water, it is questionable just how much consolidation occurs over the maximum 7-day period. Within a lacustrine field environment, however, Droppo and Amos (2001) found (using CT scanner analysis of sediment cores) a stratified density profile with a lower density SFGL layer (ranging from 1.0 to $1.5 \mathrm{~g} \mathrm{~cm}^{-3}$ ) of up to $8 \mathrm{~mm}$ in thickness, followed by a more consolidated bed of relatively even strength with

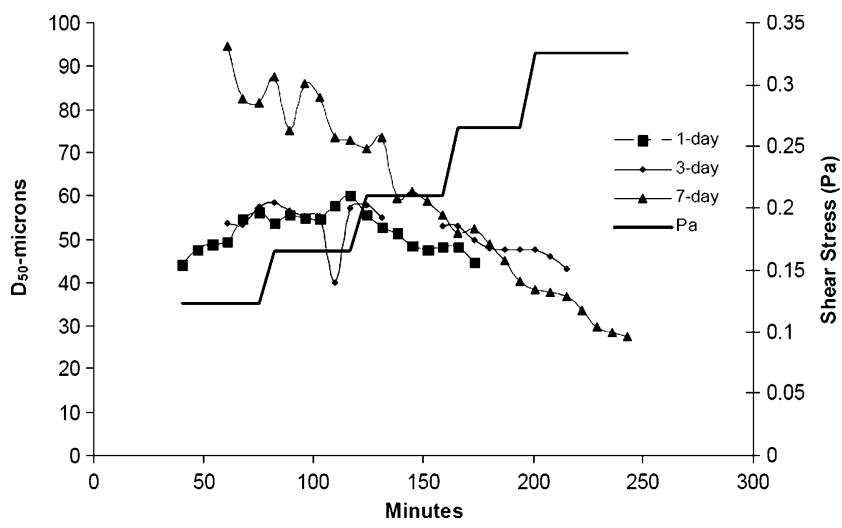

Fig. 5 Median size of eroded floc $\left(D_{50}\right)$ for different consolidation/ biostabilization periods (3-day discontinuity was due to clogging of the CILAS observation cell) 
a

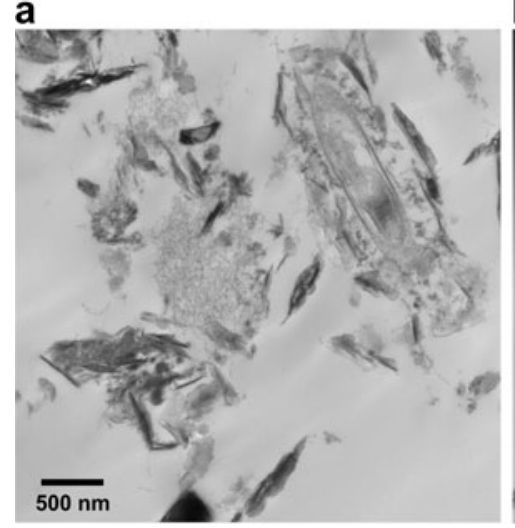

b

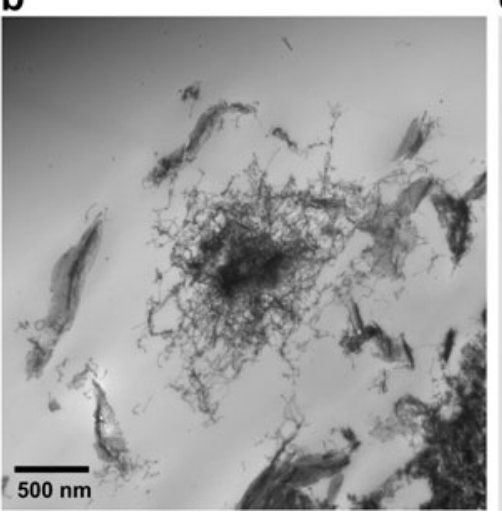

C

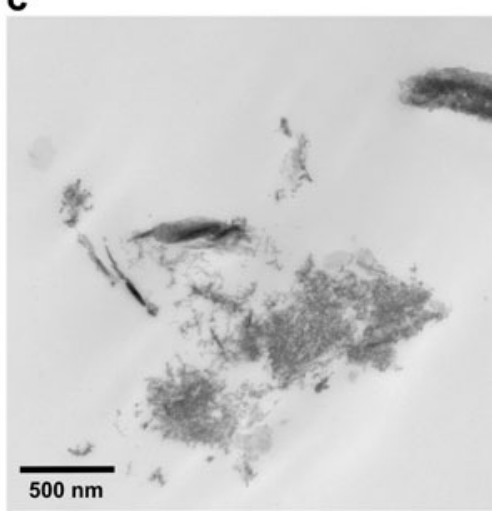

Fig. 6 Example representative TEM images (scale, $500 \mathrm{~nm}$ ) of flocs at the end of tests for different consolidation/biostabilization periods: a 1-day, b 3-day, and c 7-day

depth $\left(1.5 \pm 0.1 \mathrm{~g} \mathrm{~cm}^{-3}\right)$. Interesting, however, Amos et al. (2010) suggests that for most erosion scenarios, the majority of bed erosion occurs in the top few millimeters, and assumptions or measurements of strength (density) profiles with depth have little credibility on the control of erosion. Although, self-weighted consolidation cannot be ruled out as a process occurring within the flume, with the above information and the physical conditions of the experiments noted, it is likely that consolidation plays a lesser role in stabilizing the sediment compared to microbial mediation or biostabilization (Gerbersdorf et al. 2008; Paterson 1997). Biostabilization can be defined as the process whereby microbial growth and production of EPS in conjunction with sediment colonization by other organisms, such as fungi and algae, result in the increased stabilization of a bed sediment due to the sticking together of individual particles and flocs (Droppo et al. 2001). In essence, biostabilization represents a biofilm incorporated into the surface sediment.

Certainly there is evidence from Figs. 6 and 7 (showing two different resolutions-TEM and ESEM, respectively) of structural biological mediation of sediment flocs. The importance of individual EPS fibrils is seen in Fig. 6 while more bulk organic coverage of flocs is seen in Fig. 7. The observed filamentous stringer type flocs for the 7-day CB would further suggest that algae are playing a strong role in stabilizing the bed sediment. Yallop et al. (2000) and Gerbersdorf et al. $(2008,2009)$ have demonstrated that multiple sources of EPS binding material for bed sediment stability are generally present in sediments from both microbial and algal sources. In addition, diatoms, which were observed to be present within our sediments, are also known to produce significant quantities of EPS (Smith and Underwood 1998) with stabilizing properties. Lundkvist et al. (2007) found that diatom colonization of cohesive sediments increase the critical shear stress for erosion by $120 \%$ compared to only $20 \%$ for bacteria. Future research proposed for the Athabasca River oil sands region will elucidate the role of biological mediation on bed sediment stability in more detail than could be achieved here.

Our bacterial results, while limited, were contrary to the expected increase in bacterial counts with $\mathrm{CB}$ time. Instead,

\section{a}

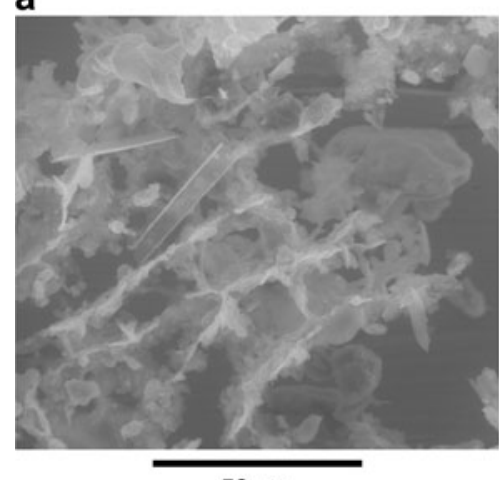

$50 \mu \mathrm{m}$ b

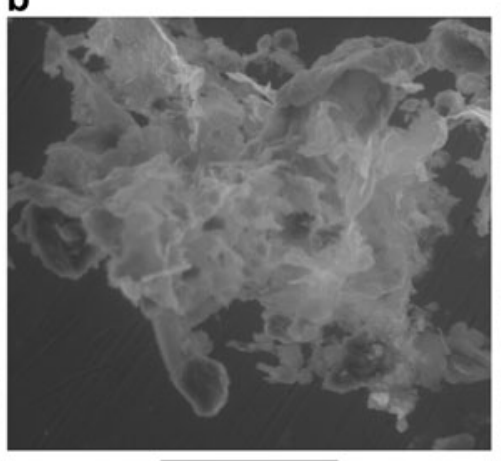

$50 \mu \mathrm{m}$

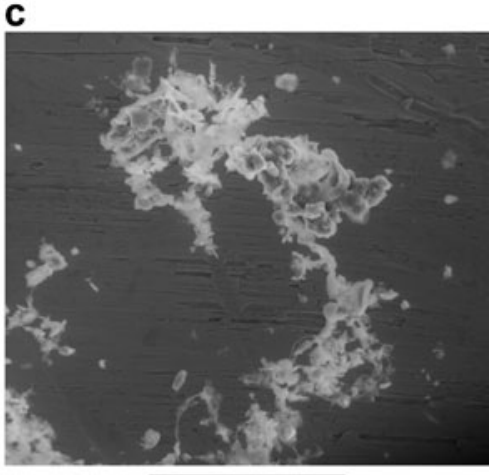

$100 \mu \mathrm{m}$

Fig. 7 Example representative ESEM images of flocs at the end of tests for different consolidation/biostabilization periods: a 1-day (scale, $50 \mu \mathrm{m}$ ), b 3-day (scale, $50 \mu \mathrm{m}$ ), and c 7-day (scale, $100 \mu \mathrm{m}$ ) 
Table 3 Mean POC, DOC, and SS concentrations (all units in milligrams per liter) at the start and end of each run

\begin{tabular}{|c|c|c|c|c|c|c|c|c|c|}
\hline & \multicolumn{3}{|l|}{ 1-Day } & \multicolumn{3}{|l|}{ 3-Day } & \multicolumn{3}{|l|}{ 7-Day } \\
\hline & POC & DOC & SS & POC & DOC & SS & POC & DOC & SS \\
\hline Start & $14.3 \pm 1.1$ & $34.3 \pm 0.6$ & 185 & & $38.2 \pm 0.4$ & 35 & $2.4 \pm 0.05$ & $47.7 \pm 1.2$ & 20 \\
\hline End & $124 \pm 0.6$ & $34.2 \pm 0.1$ & 1210 & $132 \pm 6.8$ & $39.4 \pm 0.2$ & 550 & $84.0 \pm 0.5$ & $53.2 \pm 0.6$ & 230 \\
\hline Ratio (end/start) & 8.7 & 1.0 & 6.5 & NA & 1.0 & 15.7 & 34.8 & 1.1 & 11.5 \\
\hline
\end{tabular}

Note that the "end" SS concentration was based on a sample collected at 200 min within each run. This was necessitated to provide a standard sampling time, given each erosion experiment was run for different lengths of time; $n=3$ for POC and DOC

concentrations declined with time. This decline, however, may in part be due to the change in community structure, with the observed increase in algae coinciding with a decrease in bacteria. Such a switching of dominant organisms was found by Droppo et al. (2007) when investigating biostabilization of cohesive sediments in a wave-dominated environment. Over a 15-day duration, gramnegative bacteria were found to decline while algal populations increased. Given that standard plate counts are not highly sensitive and assume that bacteria are planktonic, it is also possible that with time, bacteria became more incorporated into the floc material. In so doing, colony forming microbial units (CFU) may be missed within the counts (e.g., there may be hundreds of bacteria associated with a floc but they may result in only one observed CFU when the inverted filtered sample is incubated on the agar plate) (Salhani and Uelker-Deffur 1998). Further, plate counts can be highly selective (missing some microbial species) and will not account for nonviable microbes which could still have an effect on bed stability by increasing the cohesive nature of the deposit.

Measurements of eroded DOC and POC (see Table 3) were difficult to interpret as their values were highly related to the amount of SS eroded (sampling of the bed sediment directly prior to erosion experiments was not possible as this would have compromised the integrity of the bed surface). Given that SS concentration varied significantly between CBs at the same period of erosion due to variations in bed stability, comparisons of absolute values have limited utility. For example, the 7-day CB POC was less than that for the 1-day $\mathrm{CB}$; however, after $200 \mathrm{~min}$ of erosion, the SS concentration was almost ten times that of the 7-day CB experiment. The indication that POC may be reflective of some stabilizing condition, however, is weakly reflected within the relative value (ratio) of POC measured at the beginning and end of the experiment where the 7-day CB POC increased by 35 times compared to only nine times for the 1-day CB. DOC did increase marginally from the 1- to 7-day $\mathrm{CB}$; however, the relative increase from the start to end of the experiments did not change suggesting a lack of influence of SS concentration on this value and a poor relationship to bed stability.
The suggestion that biological mediation plays a strong role in the bed sediment stability, along with the possibility of some self-weighted consolidation is supported by the experimental results from the flume. Figure 1 illustrates that regardless of shear level, the 7-day CB consistently yielded the lowest eroded SS concentration with the 3-day CB resulting in an intermediate concentration. This inverse relationship between bed stability and CBs suggests that more energy is required to suspend an equivalent amount of sediment relative to lower CBs. This is also seen in the increasing shear required to generate types Ia and $\mathrm{Ib}$ erosion with CBs. The critical bed shear stress for erosion $\left(\tau_{\mathrm{c}}\right)$ increased from 0.16 to $0.26 \mathrm{~Pa}$ for 1- and 7-day CBs, respectively. Interestingly, the amount of shear required to move erosion from type Ia to $\mathrm{Ib}$ for all $\mathrm{CBs}$ was consistently one increment in shear $(0.05 \mathrm{~Pa})$. Perhaps, a narrower range in shear increments would have delineated the differences in more detail.

The values of $\tau_{\mathrm{c}}$ reported here are at the high end of those reported by Droppo (2009) for freshwater environments and on the low end of those reported for multiple marine environments by Amos et al. (2003). However, it should be noted that no sieving was performed on these sediments as was done in this study. Sieving was required to assess the true effects of the cohesive sediments as a large mix of sediment sizes were within the bed up to and including cobles. Further, the values reported by Droppo (2009) and Amos et al. (2003) used type $\mathrm{Ib}$ as the $\tau_{\mathrm{c}}$ whereas our work focused on the SFGL and used type Ia for $\tau_{\mathrm{c}}$. In addition, the results of Droppo (2009) were generated using a 2-m annular flume which may have not generated even shear across the bed, possibly skewing the results. The 5-m flume is believed to provide a more even distribution of bed shear (Petersen and Krishnappan 1994).

Erosion rates commonly show significant variation in time for a given shear level with an initial spike when a new shear is applied followed by a reduction in the erosion rate as new layers of possibly structurally different sediment are reached. This variation in erosion rate is due to different consolidation, water content, or microbial mediation at different levels in the sediment (Amos et al. 
2003). With a further increase in shear, the rate will spike again and then gradually decline again at the same shear. While Fig. 2 simplifies erosion rate by using an average rate constant for each $\mathrm{CB}$, it does further support the observation of increasing bed strength with $\mathrm{CB}$ time.

Once particles are eroded from the bed, their structure and strength will play a strong role in their transport and fate within any aquatic system. Very large flocs with an open matrix (low porosity) will be more prone to breakage than smaller, more dense flocs (Milligan and Hill 1998). In general, the larger the floc, the faster its settling velocity is (see Fig. 4b); however, its transport dynamics within the water column will be dictated by its interactions with the shear stresses imparted onto the floc. Droppo (2004) has used the concept of "floc recycling" to conceptually illustrate the "life cycle" of a floc with its transient interactions with the bed and fluid shear, and the continual formation and break-up of flocs in suspension.

Figure 3 and Table 2 have illustrated that the 7-day CB, while initially yielding the largest flocs, also produced the weakest flocs relative to the 1- and 3-day CBs. This is supported by the visual observations of large organic rich flocs within the flume that were seen to break up with increasing shear and by the ESEM observation of more open elongated matrices (see Fig. 7c). The more tightly bound eroded flocs of the 1-day and 3-day CBs were more stable than the more open matrix of the 7-day eroded flocs which can be easily broken by fluid shear. The likely thicker buoyant biofilm formed on the 7-day CB bed may have possessed an upward effective stress larger than the biofilm strength and hence allowed for easier floc erosion with subsequently break-up within the flow (Amos et al. 2003; Sutherland et al. 1998). Further, Fig. 5 corroborates this finding by illustrating a rapid decline in particle size with time (shear) for the 7-day CB relative to the others. The lower rates of change in eroded floc size with increasing shear for the 1- and 3-day runs suggest that they may have stronger bonding. It is interesting to note, however, that after approximately $120 \mathrm{~min}$, all CBs had similar rates of change with shear (slopes) suggesting a possible similar core floc strength. Liao et al. (2002), within the wastewater literature, has demonstrated a twolayer floc model with an outer defuse and easily removable layer around an inner more dense and stable core. It is possible that the 7-day $\mathrm{CB}$ flocs initially possessed these two layers, and once the first layer was eroded, only the inner core was left with flocs similar to the other $\mathrm{CBs}$ in size. The strongest flocs were, nonetheless, found for the 3-day $\mathrm{CB}$ suggesting that a close to optimal association of microbes has been achieved to stabilize the floc, although this cannot be quantified. The observed increase in floc $D_{50}$ for the 1- and 3-day CBs over the initial $80 \mathrm{~min}$ of the experiment (shear change from 0 to $0.121 \mathrm{~Pa}$ ) (see Fig. 5), suggests that either (a) larger flocs are being brought into suspension, or (b) flocculation is occurring in suspension to increase the measured size. Following the coarsening of the distributions, however, the floc $D_{50}$ gradually decreases for both $\mathrm{CBs}$, suggesting that the flocs are breaking up as shear continues to increase.

\section{Implications}

It is well established that contaminants, including PAHs (a contaminant of relevance to the Athabasca oil sands area), possess a high affinity for sediments, particularly the cohesive fraction (e.g., Ghosh et al. 2000; Headley et al. 2001; Maruya et al. 1996). While the results presented here were generated from sediment $(<200 \mu \mathrm{m})$ collected at the confluence of the Muskeg River and Athabasca River, they are applicable to the general fine sediment material that can be eroded within the watersheds of the Athabasca oil sands area. The range of $\tau_{\mathrm{c}}$ measured within the flume (0.16-0.26 Pa-1- and 7-day CBs), and even the more erosive type $\mathrm{Ib}$ shear for erosion $(0.21-0.31 \mathrm{~Pa}$ ) (see Table 1), was found to be within the range of values stated by Amos et al. (2003) and Droppo (2009) for multiple environments. It is clear that given the size and flows of the Athabasca River, the $\tau_{\mathrm{c}}$ will be easily surpassed resulting in a downstream migration of fine sediments and associated contaminants. In a survey of fine bed sediment PAHs from multiple tributaries within the Athabasca oil sands area, Headley et al. (2001) found elevated values within the tributaries compared to the main channel of the Athabasca River. The lower PAH values in the Athabasca River are testament to the significant erosion, transport, and dilution capacity of the river itself. Given the possible ecological impact of sediment PAHs within the oil sands area and downstream to the Lake Athabasca Delta, this paper provides critical information towards establishing the required baseline hydrodynamic conditions for the management of sediment-PAH erosion, transport, and deposition. In this regard, the paper provides information (critical bed shear stress for erosion and erosion rate) towards the development of models such as that described by Krishnappan (2000) which can be used to predict sediment and associated contaminant dynamics in the Athabasca River. Such models will be of importance for the management of disturbed watersheds within the oil sands area and in assessing the potential impact on the downstream Lake Athabasca Delta. Further, the paper demonstrates that in the management of sediment-contaminant issues, one cannot only focus on the bulk chemical concentration alone but rather must also incorporate information on 
sediment interactions, hydrodynamics, and biological characteristics of the system. Without a holistic approach to the modeling and management of water resources, erroneous decisions on contaminant transport, exposure, and risk could be made with possible detrimental impacts.

\section{Conclusions}

The results of this research demonstrate that cohesive sediment dynamics control the erosion, transport, and fate of contaminants through the symbiotic interplay between fluid shear stress and the structure, composition, and strength of the eroded flocs. In the experimental setting, consolidation was believed to have limited effect on erosion while biostabilization was the likely main controlling factor. Increasing biostabilization with time resulted in a more stable surficial layer with a reduced erosion rate relative to less biostabilized beds. The highly biostabilized bed (7-day $\mathrm{CB}$ ), however, yielded the largest flocs which broke up easily compared to those eroded from 1- and 3-day CBs. It is believed that the EPS produced by the sediment biological community is the main component of the bed and flocs that is responsible for the observed stability results. Finally, for the management, assessment of risk, and impact of PAHs on the Athabasca River system, there is a strong need to understand and model the cohesive sediment dynamics (with emphasis on the biological influences) as this is a primary driver of contaminant dynamics within the system.

Acknowledgments JG-A thanks the CONACYT Mexican funding agency for the economic support during a sabbatical at Environment Canada. We also thank the staff of Alberta Sustainable Resource Development at Fort McMurray for their support with the sampling equipment and shipping of samples.

\section{References}

Amos CL, Droppo IG, Gomez EA, Murphy TP (2003) The stability of a remediated bed in Hamilton harbour, Lake Ontario, Canada. Sedimentol 50:149-168

Amos CL, Bergamasco A, Umgiesser G, Cappucci S, Cloutier D, DeNat L, Flindt M, Bonardi M, Cristante S (2004) The stability of tidal flats in Venice Lagoon - the results of in-situ measurements using two benthic, annular flumes. J Mar Sci 51:211-241

Amos CL, Umgiesser G, Ferrarin C, Thompson CEL, Whitehouse RJS, Sutherland TF, Bergamasco A (2010) The erosion rates of cohesive sediments Venice lagoon, Italy. Cont Shelf Res 30:859 870

Berkhout N (1994) Manual "UHCM", Ultra High Concentration Meter. Delft Hydraulics, Rotterdam

Droppo IG (2004) Structural controls on floc strength and transport. Can J Civ Eng 31:569-578

Droppo IG (2009) Biofilm structure and bed stability of five contrasting freshwater sediments. Mar Fresh Wat Res 60:690-699
Droppo IG, Stone M (1994) In-channel surficial fine-grained sediment laminae (Part I): physical characteristics and formational processes. Hydrol Proc 8:101-111

Droppo IG, Amos CL (2001) The structure, stability and transformation of contaminated lacustrine surface fine-grain laminae. J Sed Res 71(5):718-727

Droppo IG, Leppard GG, Flannigan DT, Liss SN (1997) The freshwater floc: a functional relationship of water and organic and inorganic floc constituents affecting suspended sediment properties. Wat Air Soil Pollut 99:43-53

Droppo IG, Lau YL, Mitchell C (2001) The effect of depositional history on contaminated bed sediment stability. Sci Tot Environ 266:7-13

Droppo IG, Ross N, Skafel M, Liss SN (2007) Biostabilization of cohesive sediment beds in a freshwater wave-dominated environment. Limnol Oceanogr 53(2):577-589

Eaton AD, Clesceri LS, Rice EW, Greenberg AE (2005) Standard methods for the examination of water and wastewater, 21st edn. American Public Health Association, American Water Works Association, Water Environment Federation, Baltimore

Environment Canada (1994) Manual of analytical methods, v. 1. Major ions and nutrients. Environmental Conservation Service (ECD). Canadian Communications Group, Toronto

Francois RJ (1987) Strength of aluminum hydroxide flocs. Wat Res 21:1023-1030

Gerbersdorf SU, Jancke T, Westrich B (2007) Sediment properties for assessing the erosion risk of contaminated riverine sites. J Soils Sediments 7(1):25-35

Gerbersdorf SU, Jancke T, Westrich B, Paterson DM (2008) Microbial stabilization of riverine sediments by extracellular polymeric substances. Geobiology 6:57-69

Gerbersdorf SU, Bittner R, Lubarsky H, Manz W, Paterson DM (2009) Microbial assemblages as ecosystem engineers. J Soils Sediments 9:640-652

Ghosh U, Gillette JS, Luthy RG, Zare RN (2000) Microscale location, characterization, and association of polycyclic aromatic hydrocarbons on harbour sediment particles. Env Sci Tech 34:1729-1736

Hawley N (1982) Settling velocity distribution of natural aggregates. J Geophys Res 87(C12):9489-9498

Headley JV, Akre C, Conly FM, Peru KM, Dickson LC (2001) Preliminary characterization and source assessment of PAHs in tributary sediments of the Athabasca river, Canada. Environ Forensis 2:335-345

Jarvis P, Jefferson B, Gregory J, Parsons SA (2005) A review of floc strength and breakage. Wat Res 39:3121-3137

Krishnappan BG (1993) Rotating circular flume. J Hydraul Eng 119 (6):758-767

Krishnappan BG (2000) Modelling cohesive sediment transport in rivers. In: Stone $\mathrm{M}$ (ed), The role of erosion and sediment transport in nutrient and contaminant transfer. Proceedings of the International Association for Hydrological Sciences, Waterloo, Ontario, Canada, IAHS Pub 263, pp 269-276

Krishnappan BG (2007) Recent advances in basic and applied research in cohesive sediment transport in aquatic systems. Can J Civ Eng 34:731-743

Krumbein WE, Paterson DM, Stal LJ (eds) (1994) Biostabilization of sediments. Verlag, Oldenburg, p 526

Lambert CP, Walling DE (1988) Measurement of channel storage of suspended sediment in a gravel-bed river. Catena 15:6580

Larkin PA (1978) Biometrics - a handbook of elementary statistical tests. University of British Columbia, Vancouver, British Columbia, Canada

Liao BQ, Allen DG, Leppard GG, Droppo IG, Liss SN (2002) Interparticle interactions affecting the stability of sludge flocs. J Colloid Interf Sci 249:372-380 
Liss SN, Droppo IG, Flannigan D, Leppard GG (1996) Floc architecture in wastewater and natural riverine systems. Env Sci Tech 30(2):680-686

Lundkvist M, Grue M, Friend PL, Flindt MR (2007) The relative contributions of physical and microbiological factors to cohesive sediment stability. Contin Shelf Res 27(8):1143-1152

Maruya KA, Risebrough RB, Horne AJ (1996) Partitioning of polynuclear aromatic hydrocarbons between sediments from San Francisco Bay and their porewaters. Env Sci Tech 30:2942-2947

Milligan TG, Hill PS (1998) A laboratory assessment of the relative importance of turbulence, particle composition, and concentration in limiting maximal floc size and settling behavior. J Sea Res 39:227-241

Parker DS, Kaufman WJ, Jenkins D (1972) Floc breakup in turbulent flocculation processes. J Sanit Eng Div: Proc ASCE SA1:79-99

Paterson DM (1997) Biological mediation of sediment erodibility: ecology and physical dynamics. In: Burt N, Parker R, Watts J (eds) Cohesive sediments. John Wiley, New York, pp 215-229

Petersen O, Krishnappan BG (1994) Measurement and analysis of flow characteristics in a rotating circular flume. J Hydraul Res 32 (4):483-494
Ravens TM, Gschwend PM (1999) Flume measurements of sediment erodibility in Boston harbor. J Hydraul Eng 125(10):998-1005

Salhani N, Uelker-Deffur A (1998) Improved quantification of aggregated bacteria by combined enzymatic and mechanical treatment of flocs and biofilms from a rotating drum bioreactor. Wat Res 32:1287-1295

Smith DJ, Underwood JC (1998) Exopolymer production by intertidal epipelic diatoms. Limnol Oceanogr 43(7):1578-1591

Stone M, Krishnappan BG, Emelko MB (2008) The effect of bed age and shear stress on the particle morphology of eroded cohesive river sediment in an annular flume. Wat Res 42:4179-4187

Sutherland TF, Amos CL, Grant J (1998) The effect of buoyant biofilms on the erodibility of sublittoral sediments of a temperate microtidal estuary. Limnol Oceanogr 43(2):225-235

Teisson C, Ockenden M, Le Hir P, Kranenburg C, Hamm L (1993) Cohesive sediment transport processes. Coastal Eng 21:129-162

Yallop ML, Paterson DM, Wellsbury P (2000) Interrelationships between rates of microbial production, exopolymer production, microbial biomass and sediment stability in biofilms of intertidal sediments. Microb Ecol 39:116-127 